\title{
molecules
}

ISSN 1420-3049

http://www.mdpi.org

\section{Hepatic Mitochondrial Redox Potential in Patients with Liver Metastatic Cancers and Circulatory Insufficiency}

\author{
Piotr Tomaszewski ${ }^{1, *}$, Grazyna Kubiak-Tomaszewska ${ }^{1}$, Jan Pachecka ${ }^{1}$, M arcin Balcerzak ${ }^{1}$, \\ Bozena Haznar ${ }^{1}$, Cezary Pszenny ${ }^{2}$, Marek Krawczyk ${ }^{2}$, Pawel Paczkowski ${ }^{2}$ and Marek Jarecki $^{3}$ \\ 1 Department of Biochemistry and Clinical Chemistry, Medical University of Warsaw, 1 Banacha St, \\ 02-097 Warsaw, Poland. Tel. (+48 22-5720769, Fax. (+48) 22-5720735 \\ 2 Department of General Surgery and Liver Diseases, Medical University of Warsaw, 1A Banacha St, \\ 02-097 Warsaw, Poland. Tel. (+48) 22-8229253, Fax: (+48) 22-6583662; e-mail: \\ hepaclin@waw.pdi.net \\ ${ }^{3}$ Central Hospital of Ministry for Home Affairs and Administration, 137 Woloska St, Warsaw, Poland. \\ * Author to whom correspondence should be addressed; e-mail: petom@farm.amwaw.edu.pl
}

\begin{abstract}
Arterial ketone body ratio (AKBR), which reflects hepatic intramitochodrial redox potential, was measured in 20 patients with Carcinoma hepatis metastaticum and good circulatory condition (group A), and 16 patients with Carcinoma hepatis metastaticum and chronic cardiogenic circulatory insufficiency (group B). Total ketone body concentration (TKB) and arterial oxygen tension $\left(\mathrm{PaO}_{2}\right)$ was simultaneously determined. We have stated that AKBR values in both groups of patients were decreased below the normal level. AKBR values in group B were significantly lower than in group A. At the same time TKB values in both groups were statistically equal and significantly increased above the normal level. The levels of arterial oxygen tension $\left(\mathrm{PaO}_{2}\right)$ in group A were physiologically high, whereas in group B were significantly decreased. Furthermore arterial oxygen tension of patients in group B correlated with AKBR values significantly. In group A we found statistically significant negative correlation between TKB and AKBR values. Our study indicate that the main mechanism which may explain the decrease of intrahepatic mitochondrial redox potential in patients with liver metastatic cancers and good circulatory condition, is the enhanced beta-oxidation of fatty acids, when the efficiency of $\mathrm{NAD}^{+}$to $\mathrm{NADH}$ reduction in beta-oxidation pathway and tricarboxylic acid cycle is higher than re-oxidation of $\mathrm{NADH}$ to $\mathrm{NAD}^{+}$in the oxidative
\end{abstract}


phosphorylation. In patients with coexisting chronic cardiogenic circulatory insufficiency deprivation of blood oxygen supply initiate the irreversible dysfunction of oxidative phosphorylation.

Keywords: mitochondrial redox potential, arterial ketone body ratio, total ketone body concentration, liver metastatic cancer, circulatory insufficiency

\section{Introduction}

Oxidative phosphorylation of ADP to produce ATP is the most important activity of the mitochondria. The main regulator of ATP production is the mitochondrial redox potential $\left[\mathrm{NAD}^{+}\right] /\left[\mathrm{NADH}+\mathrm{H}^{+}\right][6,8,16]$. Ketogenesis is a process basically confined to the liver. The initial substance from the group of ketone bodies is acetoacetate, which undergo reduction to D-(-)-3hydroxybutyrate (Scheme 1.) owing to the activity of 3-hydroxybutyrate dehydrogenase (E.C. 1.1.1.30), located within the cristae of internal membrane of mitochondria $[1,5,8,9]$.

\section{E.C. 1.1.1.30}

$$
\text { Acetoacetate }+\mathrm{NADH}+\mathrm{H}^{+} \leftrightarrow \mathrm{D}-(-)-3 \text {-hydroxybutyrate }+\mathrm{NAD}^{+}
$$

Scheme 1. Activity of 3-hydroxybutyrate dehydrogenase.

Acetoacetate and 3-hydroxybutyrate freely pass through mitochondrial and cellular membranes. Ozawa et al. was able to show that intramitochondrial $\left[\mathrm{NAD}^{+}\right] /\left[\mathrm{NADH}+\mathrm{H}^{+}\right]$ratio correlates directly with the intrahepatic and arterial [acetoacetate]/[D-(-)-3-hydroxybutyrate] ratio (AKBR). Therefore, the arterial ketone body ratio (AKBR) is a measure of the hepatic intramitochodrial redox potential and hepatic energy charge [4,5,8-10].

Beta-oxidation of fatty acids is the most important metabolic pathway which deliver the substrates for ketogenesis. Total ketone body concentration $(\mathrm{TKB}=$ [acetoacetate $]+[\mathrm{D}-(-)-3$-hydroxybutyrate $])$ reflect the effectiveness of these both pathways $[9,11]$.

The aim of this study is to evaluate the hepatic intramitochondrial redox potential (measured as AKBR) in patients with liver metastatic cancers and chronic cardiogenic circulatory insufficiency, in relation to the effectiveness of fatty acids oxidation and ketogenesis, measured as TKB.

\section{Results and Discussion}

Thirty six patients with similar location and extent of liver metastatic cancers (Carcinoma hepatis metastaticum) in the left surgical lobe of the liver (segments II, III or II, III, IV) [2] were classified into two groups: group A consisted 20 patients with Carcinoma hepatis metastaticum and good circulatory 
condition, and group B consisted 16 patients with Carcinoma hepatis metastaticum and chronic cardiogenic circulatory insufficiency (Table 1.).

Table 1. Characteristics of the study groups

\begin{tabular}{|l|c|c|}
\cline { 2 - 3 } \multicolumn{1}{c|}{} & Group A & Group B \\
\hline Diagnosis & $\begin{array}{c}\text { Carcinoma hepatis metastaticum } \\
\text { and good circulatory condition }\end{array}$ & $\begin{array}{c}\text { Carcinoma hepatis metastaticum } \\
\text { and chronic cardiogenic } \\
\text { circulatory insufficiency }\end{array}$ \\
\hline Number of patients & $\mathrm{N}=20$ & $\mathrm{n}=16$ \\
\hline Age interval & $31-71$ years & $39-72$ years \\
\hline $\begin{array}{l}\text { Sex (female/male) } \\
\text { Location and ext ent of metastatic tumor: }\end{array}$ & $11 / 9$ & $7 / 9$ \\
\hline $\begin{array}{c}\text { segments II, III } \\
\text { segments II, III, IV }\end{array}$ & 6 patients $(30 \%)$ & 4 patients $(25 \%)$ \\
\hline $\mathrm{AKBR}$ & 14 patients $(70 \%)$ & 12 patients $(75 \%)$ \\
\hline $\mathrm{TKB}[\mu \mathrm{mol} / \mathrm{L}]$ & $0.54 \pm 0.03$ & $0.10 \pm 0.02$ \\
\hline $\mathrm{PaO}[\mathrm{kPa}]$ & $355.40 \pm 43.55$ & $430.00 \pm 61.25$ \\
\hline
\end{tabular}

We have stated that AKBR values in both groups of patients were decreased below the normal level $(<0.7)$. AKBR values in group B: $0.10 \pm 0.02$ were significantly lower $(\mathrm{P}<0.0001)$ than in group A: $0.54 \pm 0.03$ (Figure 1.). At the same time TKB values in both groups (A: $355.40 \pm 43.55 \mu \mathrm{mol} / \mathrm{L}$; $\mathrm{B}$ : $430.00 \pm 61.25 \mu \mathrm{mol} / \mathrm{L})$ were statistically equal $(\mathrm{P}=0.3156)$ and significantly increased above the normal level. The levels of arterial oxygen tension $\left(\mathrm{PaO}_{2}\right)$ in group $\mathrm{A}: 11.0 \pm 0.3 \mathrm{kPa}$ were physiologically high, whereas in group $\mathrm{B}: 7.9 \pm 0.2 \mathrm{kPa}$ were significantly decreased $(\mathrm{P}<0.0001)$. Furthermore arterial oxygen tension of patients in group $\mathrm{B}$ correlated with AKBR values significantly $\left(\mathrm{r}^{2}=0.967\right.$, $\mathrm{P}<0.0001$; Figure 2.). In group $\mathrm{A}$ we did not find the similar interdependence. On the other hand we found in group A statistically significant negative correlation $\left(\mathrm{r}^{2}=0.815, \mathrm{P}<0.0001\right.$; Figure 3.) between TKB and AKBR values, which did not exist in group B. 


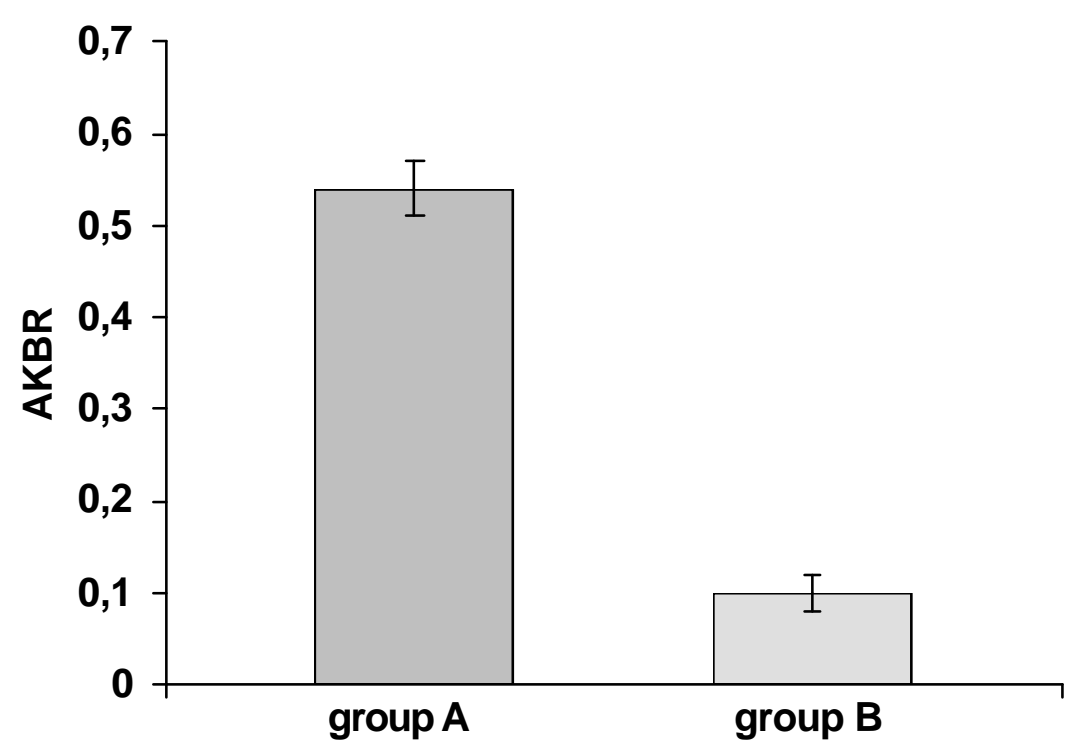

Figure 1. AKBR values (mean \pm SEM) in 20 patients with Carcinoma hepatis metastaticum and good circulatory condition (group A) and 16 patients with Carcinoma hepatis metastaticum and chronic cardiogenic circulatory insufficiency (group B).

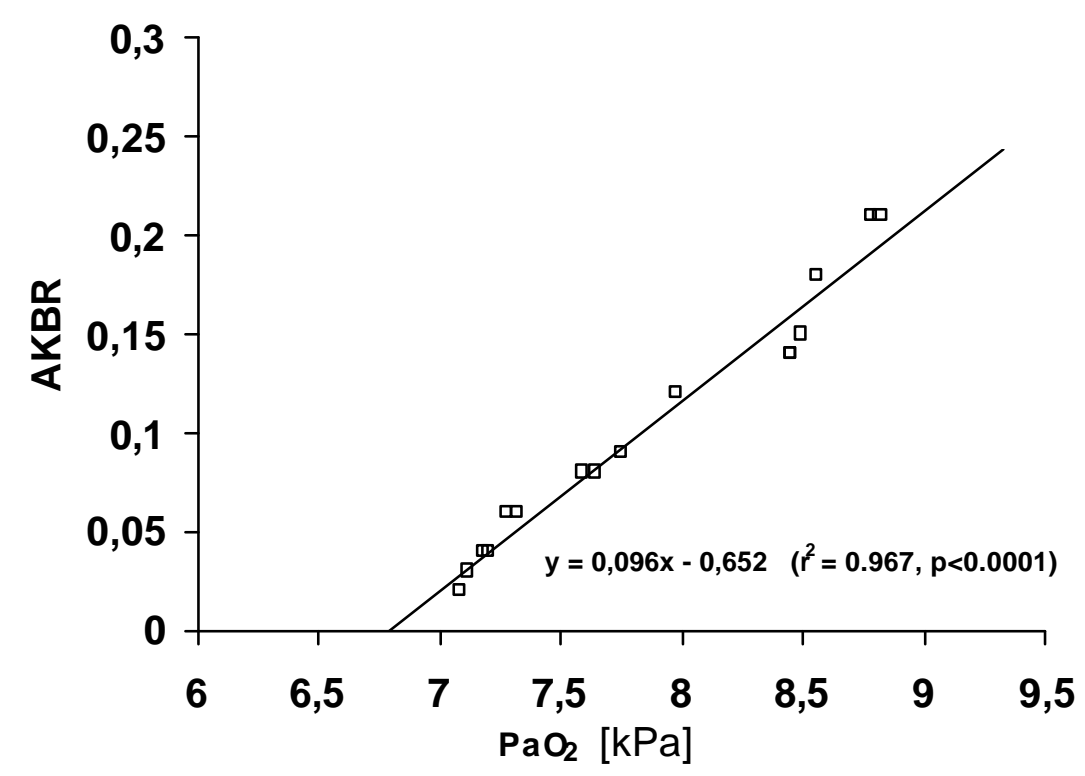

Figure 2. The relationship between arterial ketone body ratio (AKBR) and arterial oxygen tension $\left(\mathrm{PaO}_{2}\right)$ in patients with Carcinoma hepatis metastaticum and chronic cardiogenic circulatory insufficiency (group B). 


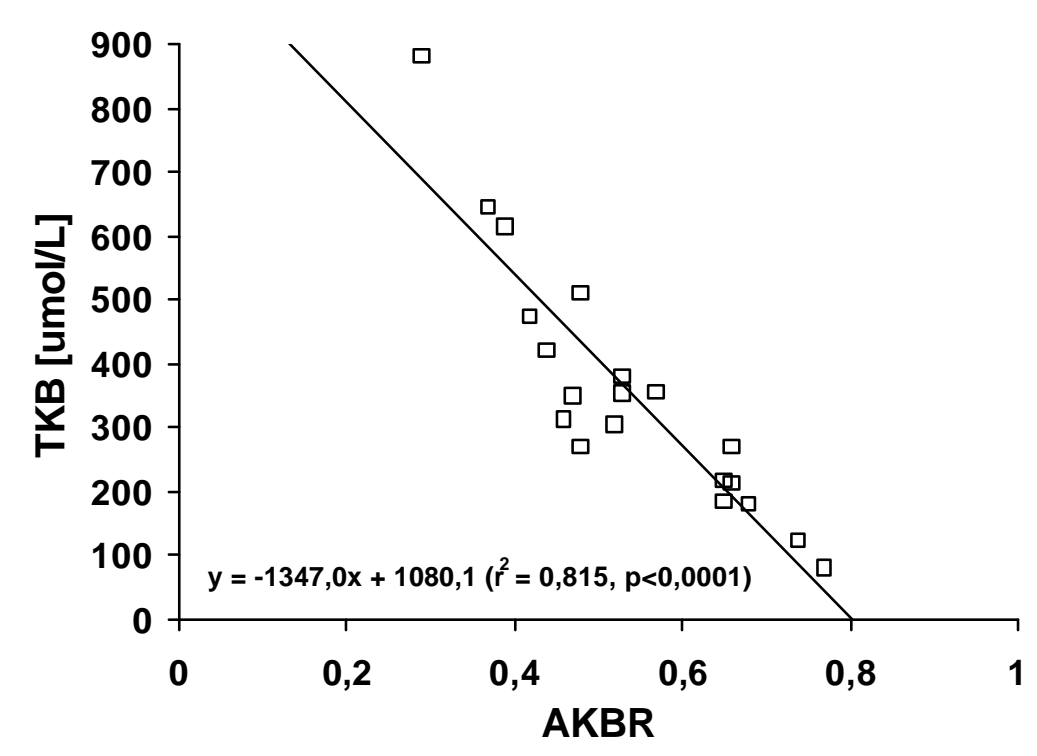

Figure 3. The relationship between total ketone body concentration (TKB) and arterial ketone body ratio (AKBR) in patients with Carcinoma hepatis metastaticum and good circulatory condition (group A).

The high total ketone body concentrations (TKB) and the significant correlation between TKB and $A K B R$ values in group $A$ indicate, that the main mechanism which may explain the observed in group A moderate decrease of intrahepatic mitochondrial redox potential, measured as AKBR, is the acceleration of beta-oxidation of fatty acids as a compensatory energetic mechanism, according to conclusions from the study of Shimahara et al. [11]. Our results correspond to the observations of the above-cited authors, that fatty acids oxidation is significantly enhanced around the critical zone of AKBR (near 0.4), resulting in increased ketogenesis. When the efficiency of $\mathrm{NAD}^{+}$to NADH reduction in beta-oxidation pathway and tricarboxylic acid cycle is higher than reoxidation of NADH to $\mathrm{NAD}^{+}$in the oxidative phosphorylation, then increase reduction of acetoacetate to D-(-)-3hydroxybutyrate. Alternative mechanisms which may explain decrease of intrahepatic mitochondrial redox potential, like the local hemodynamic disorders provoked by the pressure of growing tumor $[5,8,13]$ or the enhancement of beta-oxidation of fatty acids owing to the enormous energy requirements of proliferous cancer, may have only secondary importance.

Deep oxygen deficit generate by chronic cardiogenic circulatory insufficiency is the main mechanism which explain the significant decrease of AKBR values in group $B$. The significant correlation between arterial oxygen tension and AKBR values in this group is the important argument for this thesis. Deprivation of blood oxygen supply causes inhibition of the electron transport system in 
the internal membrane of mitochondria. It was stated that these critically low values of AKBR $(<0.25)$ reflects the irreversible dysfunction of oxidative phosphorylation $[3,6,7,12]$.

\section{Conclusions}

Our study indicates that the main mechanism which may explain the decrease of intrahepatic mitochondrial redox potential in patients with liver metastatic cancers and good circulatory condition, is the enhanced beta-oxidation of fatty acids, when the efficiency of $\mathrm{NAD}^{+}$to NADH reduction in betaoxidation pathway and tricarboxylic acid cycle is higher than re-oxidation of $\mathrm{NADH}$ to $\mathrm{NAD}^{+}$in the oxidative phosphorylation. In patients with coexisting chronic cardiogenic circulatory insufficiency deprivation of blood oxygen supply initiate the irreversible dysfunction of oxidative phosphorylation.

\section{Experimental}

Arterial blood samples from 36 patients (18 women, 18 men) with liver metastatic cancers (Carcinoma hepatis metastaticum) were analysed. Only the patients with similar location and extent of the metastatic tumors (left surgical lobe of the liver [2], segments II, III or II, III, IV) were selected to the present study. Patients were classified into two groups: group A consisted 20 patients (11 women, 9 men) with Carcinoma hepatis metastaticum ages from 31 to 71 years with good circulatory condition and group B consisted 16 patients ( 7 women, 9 men) ages from 39 to 72 years with Carcinoma hepatis metastaticum and chronic cardiogenic circulatory insufficiency (Table 1). The blood samples were taken from the femoral artery of patients one day before partial hepatectomy in the presence of an adequate glucose load (blood glucose $\approx 2 \mathrm{~g} / \mathrm{l}$ ), without standard hospital feeding. AKBR was calculated as a ratio of acetoacetate and 3-hydroxybutyrate concentrations in arterial blood, measured by the enzymatic methods according to Williamson and Mellanby [14,16], with spectrophotometric detection at wavelength $340 \mathrm{~nm}$. Total ketone body concentration (TKB) was simultaneously calculated, as a sum of acetoacetate and 3-hydroxybutyrate concentrations. The measurement of both ketone bodies is a simple and noninvasive procedure requiring $2 \mathrm{ml}$ of arterial blood per examination, and results can be obtained within $60 \mathrm{~min}$. Blood gas analysis was simultaneously performed (Table 1). All results are expressed as means \pm SEM. Statistical analysis was performed by Student's $t$ test and analysis of variance. Linear regression analysis was used to determine the correlations between arterial oxygen tension and AKBR or TKB values. $\mathrm{P}$ values less than 0.05 were regarded as statistical significant.

\section{References}

1. Chapman, M.J.; Miller, L.R.; Ontro, T.A. Localization of the Enzymes of Ketogenesis in Rat Liver Mitochondria. J. Cell. Biol. 1973, 58, 284-306.

2. Couinaud, C. Distribution de l'artére hépapique dans le foie. Acta Anat. 1954, 22, 49-81. 
3. Gubernatis, G.; Bornscheuer, A.; Taki, Y.; Farle, M.; Lübbe, N.; Yamaoka, Y.; Beneking, M.; Burdelski, M.; Oellerich, M. Total Oxygen Consumption Ketone Body Ratio and a Special Score as Early Indications of Irreversible Liver Allograft Dysfunction. Transplant. Proc. 1989, 21, 22792281.

4. Gutiérrez-Salinas, J.; Miranda-Garduño, L.; Trejo-Izquierdo, E.; Díaz-Muñoz, M.; Vidrio, S.; Morales-Gonzáles, J. A.; Hernández-Muñoz, R. Redox State and Energy Metabolism during Liver Regeneration. Alterations Produced by Acute Ethanol Administration. Biochem. Pharmacol. 1999, 58, 1831-1839.

5. Iwata, S.; Ozawa, K.; Shimahara, Y.; Mori, K.; Kobayashi, N.; Kumada, K.; Yamaoka, Y. Diurnal Fluctuations of Arterial Ketone Body Ratio in Normal Subjects and Patients with Liver Dysfunction. Gastroenterology 1991, 100, 1371-1378.

6. Katsuyama, K.; Ozawa, K. M.; Morikawa, S.; Iwata, S.; Mori, A. Myocardial High-energy Phosphates and Hepatic Redox State in Jaundiced Rats. J. Surg. Res. 1999, 82, 88-94.

7. Kiyama, H. Significance of Arterial Ketone Body Ratio as a Parameter of Oxygen Metabolism in Cardiac Surgery. Nippon Kyobu Geka Gekkai Zasshi 1997, 45, 1525-1531.

8. Ozawa, K.; Aoyama, H.; Yasuda, K.; Shimahara, Y.; Nakatani, T.; Tanaka, J.; Yamamoto, M.; Kamiyama, Y.; Tobe, T. Metabolic Abnormalities Associated with Postoperative Organ Failure. A Redox Theory. Arch. Surg. 1983, 118, 1245-1251.

9. Pardela, M. S.; Lemiszewski, A. Prognostic Value of Arterial Ketone Body Ratio (AKBR) in Evaluation of The Early Liver Survival After Transplantation or Extend Hepatectomy in Adults. Med. Sci. Monit. 1999, 5, 585-590.

10. Pszenny, C.; Krawczyk, M.; Paluszkiewicz, R.; Hevelke, P.; Zieniewicz, K.; Grzelak, I.; Tomaszewski, P.; Kuczynska, J.; Pachecka, J. Biochemical Function of the Donor Liver in Living Related Liver Transplantation. Transplant. Proc. 2002, 34, 621-622.

11. Shimahara, Y.; Yamamoto, N.; Kobayashi, N.; Ozawa K. In Surgical Nutrition: Strategies in Critically Ill Patients; Latifi, R.; Dudrick, S.J., Ed.;Springer-Verlag: New York, 1995; p 171.

12. Takahashi, M.; Ueda, K.; Tabata, R.; Iwata, S.; Ozawa, K.; Uno, S.; Kinoshita, M. Arterial Ketone Body Ratio as a Prognostic Indicator in Acute Heart Failure. J. Lab. Clin. Med. 1997, 129, 72-80.

13. Tomaszewski, P.; Kubiak, G.; Pachecka, J. Hepatic Mitochondrial Redox Potential in Patients with Liver Cancers. Fol. Histochem. Cytobiol. 1999, 37, suppl.1, 17.

14. Uno, S.; Ito, S.; Kurono, M.; Yamaoka, Y.; Kamiyama, Y.; Ozawa, K. A Simple and Sensitive Assay for Blood Ketone Bodies Using Highly Purified 3-Hydroxybutyrate Dehydrogenase. Clin. Chim. Acta 1987, 168, 253-255.

15. Williamson, D. H.; Lund, P.; Krebs, H. A. The Redox State of Free Nicotinamide Adenine Dinucleotide in The Cytoplasm and Mitochondria of Rat Liver. Biochem. J. 1967, 103, 514-527.

16. Williamson, D.H.; Mellanby, J.; Krebs, H. Enzymatic Determination of D-(-)- $\beta$-hydroxybutyric Acid and Acetoacetic Acid in Blood. Biochem. J. 1962, 82, 90-96.

(C) 2003 by MDPI (http://www.mdpi.org). Reproduction is permitted for noncommercial purposes. 